\title{
RESEARCHING PAIN - RE-SEARCHING THE RESEARCHER: PULLING BACK THE CURTAIN ON THE INNER LIFE AND ANXIETY OF THE INVESTIGATOR
}

\section{James P. Anglin and Angela Scott}

\begin{abstract}
Seldom do researchers comment on or discuss in their publications the impact of their research on themselves, nor do they explore the impact of their emotions on their research data gathering or findings. The authors provide excerpts from two of their own research studies to illustrate some of the personal dimensions which they, along with George Devereux, claim are central and significant in the process of social science research. We suggest that is it is important to introduce new researchers to the psychoemotional dimensions of the researcher's own experiences in the research process in order to both sensitize them to potential research findings (often hidden), and prepare them for the possible (even likely) impacts on themselves as researchers, professionals, and human beings.
\end{abstract}

Keywords: researching pain, embodied knowing, research anxiety, pain-based behaviour

James Anglin PhD is Professor Emeritus in the School of Child and Youth Care at the University of Victoria, BC, Canada. He can be reached at \#78, 1255 Wain Road, North Saanich, BC, Canada V8L 4R4. Email: janglin@uvic.ca

Angela Scott MA currently practices as a child, youth, and family therapist at the Victoria Child Abuse Prevention and Counselling Centre, \#210 - 1175 Cook Street, Victoria, BC, Canada V8V 4A1. Email: angela.scott@vcapcc.com 
International Journal of Child, Youth and Family Studies (2019) 10(2-3): 142-155

\begin{abstract}
A Note on Style
The authors of this article have chosen to write in an informal style, using their first names rather than their last names, and avoiding such traditional phrases as "the first author" and "the second author." We do this for two reasons. First, it seemed awkward and stilted to us to write in this manner, given our subject matter. Second, impersonal language seemed to belie the very heart of our argument, namely that social science researchers are necessarily and importantly involved in their research in very personal ways. We hope readers will not be unduly put off by our use of first names, and that this informal style may even be experienced as more appropriate to our subject and theoretical position.

As well, the spellings used in the source publications from which the Prefaces are abstracted are left as they were in the originals. Jim tended to use English spellings (e.g., realising, analyse), while Angela used American spellings (e.g., analyzing).
\end{abstract}


This article is not the one we initially planned to write. We were going to report on the study that Angela undertook for her Master's degree while at the School of Child and Youth Care at the University of Victoria (Scott, 2016), and that was used also for a report by the two of us to the British Columbia Ministry of Children and Family Development (Anglin \& Scott, 2016). However, as we began to discuss this article, we realized how both of us had been deeply moved and intimately impacted, in different ways, in our research studies with young people with lived experience in care who suffered from profound and ongoing psychoemotional pain. As we talked, we were aware how researchers are affected in quite profound ways by their research engagements, especially with people who have experienced complex trauma. However, researchers typically refrain from mentioning any of this in their research reports and articles, except perhaps for occasional fleeting comments in their prefaces.

For example, in his book Children's Homes, David Berridge stated in the Acknowledgements section: "I am particularly grateful ... to the children for re-living and recounting some of the pain which they and their families had endured and which we can hardly begin to understand" (Berridge, 1985, p. vii). It is evident that the experience of pain and its effects on the children made a significant impression on the senior researcher and his research team; however, the children's pain experiences are not explored in the study, nor is the word pain ever used again in the book. Presumably, the framework and method for Berridge's research study did not bring forward this aspect of the daily life of the children's homes, and as a result the research focused much more on the children's behaviours and behavior management issues experienced by the staff. In a review of selected publications on residential group care for young people, those that were practice-oriented as well as more formal research studies, glossing over experiences of pain (both of the children and the researchers) appeared to be common practice (Anglin, 2002, pp. 133151).

When Jim was on sabbatical in the United Kingdom in the 1980s, he spent many joyous hours in bookshops, and during one foray into a favourite haunt, he stumbled upon From Anxiety to Method in the Behavioral Sciences by George Devereux (1967). Over the years, the core message of this text has continued to resonate; it is one of the few books we have found that explores deeply the phenomenon of the impact of social science research on the researcher herself or himself. Devereux's thesis is the following:

In short, behavioral science data arouse anxieties, which are warded off by a countertransference inspired pseudo-methodology; this maneuver is responsible for nearly all the defects of behavioral science. (p. xvii)

The behavioral scientist cannot ignore the interaction between the subject and observer in the hope that, if he [sic] but pretends long enough that it does not exist, it will just quietly go away. (p. xviii) 
In our minds, Devereux, in referring to the researcher's reaction as "anxiety", is using a more psychoanalytic term for the researcher's own "pain-based behaviour", which is often, but perhaps not always, in response to the pain and pain-based behaviour of the subjects of the research. This article seeks to pull back the curtain on both the challenges and potential transformations for researchers inherent in the processes of social science research, and especially research with persons living with deep and profound psychoemotional pain as the result of experiencing complex trauma. In Jim's study, some of the core findings of the research emerged from paying attention to what has been termed embodied knowing (Heshusius \& Ballard, 1996, Ch. 1) or tacit knowledge (Polanyi, 1966, 2009). In Angela's study, she was led to some deep resolutions within her personal psychoemotional and family life.

In keeping with our intention to explore the experiential dimensions of researcher engagement with subjects, and the implications of these experiences for both the nature and selfimpacts of the research findings, we will share the personal reflections that we included in the reports on two of our own studies. The first excerpt is abstracted from the book Jim published in 2002 that utilized the grounded theory method (Glaser \& Strauss, 1967) to develop a theoretical framework for what constitutes a well-functioning group home for young people removed from their families. Over a 14-month process of data gathering, Jim visited — at various times of day and night - 10 residential group facilities for young people, immersing himself in the daily life of the homes, the children, the workers, and the child welfare system in British Columbia. After many months of interviews, conversations, and observations, it became evident that responding to pain (both the children's and their own) was the core challenge for group home child and youth care workers. It was this realization that led to the emergence of the concept of "pain-based behaviour", and its naming (Anglin, 2002, pp. 107-121).

Angela was an experienced practitioner when she began her Master's degree in the School of Child and Youth Care at the University of Victoria in British Columbia, Canada. After many years of contemplating what she could do to be a better child and youth care practitioner and advocate for young people in the child welfare system and residential settings, she decided it was time to further her knowledge and education, so she applied and was accepted to the Master's program in Child and Youth Care. When she came to the university, she immediately sought out Jim to be her supervisor as she knew we had a shared experience in direct residential practice. We had many discussions about our experiences working in residential care and the child welfare system. Fortuitously, we became aware of a funding opportunity and we were successful in receiving support to study the linkages between three elements of the child welfare system in British Columbia: the process of removal of children from their families, placement transitions while in care, and the children's experiences of historical and system-related trauma (Scott, 2016). Over the course of her study, Angela interviewed 20 young people (ages 19 to 25) who had lived in care for at least 2 years. As will be evident in her own words, she also was impacted profoundly by this research engagement. 
International Journal of Child, Youth and Family Studies (2019) 10(2-3): 142-155

We will now present the Prefaces from both our research studies. Following these verbatim excerpts, we will explore what we understand to be their significance and some implications for the roles and responsibilities of researchers in relation to self-awareness and self-disclosure.

\section{Pain-Full Prefaces}

First, the Preface from "Pain, Normality, and the Struggle for Congruence: Reinterpreting Residential care for Children and Youth" (Anglin, 2002, pp. xvii-xviii):

\section{Discovering the Heart of Darkness}

When you have to attend to things of that sort, to the mere incidents of the surface, the reality - the reality, I tell you - fades. The inner truth is hidden (...). But I felt it all the same...

\section{Marlow, in Heart of Darkness by Joseph Conrad (1990, p. 30)}

This study of group homes for children and youth has been a true voyage of discovery. Yet it took a vivid and startling dream to help me to penetrate the "mere incidents of the surface" and to discover a disturbing but largely hidden truth.

I am walking across a snowy and frozen landscape. I am admiring the beauty of the snow-laden evergreen trees and the light patterns on the curves of the snow mounds between the trees. I am traversing a wide and flat expanse of snow, surveying the scene with an inner sense of curiosity and tranquility. Suddenly, I find myself falling downward, and I realise that I have broken through some thin ice. I had been walking across a frozen body of water without realising it. My entire body is plunged into the frigid water, and air bubbles are streaming from my mouth as I gasp at being submerged and unable to breathe. Then I wake up, still feeling the after-effects of a shock-like reaction in my body. (Field note; November 13, 1999)

It did not take long to link this dream experience to my [then] recent experiences of visiting several group residences, and in particular my conversations with one staff member. It was immediately clear to me that the cold water in the dream represented pain, and that the frozen landscape represented the busyness of daily routines that covered over the pain underneath the surface of group home life and work. And while this "inner truth" of pain had remained largely hidden from my conscious understanding for many months, I realised, like Marlow in Conrad's Heart of Darkness (1990), that I had "felt it all the same" (p. 30).

During the days immediately before this dream experience, I had been making intensive visits to three homes. In between visits, I had interviewed a number of residential workers and supervisors. On several occasions, I woke up very early in the morning with vague visceral sensations of discomfort in reaction to what I had been experiencing. But this disturbing dream was the most profound "wake up call" that I had yet experienced. It seems that what had finally 
International Journal of Child, Youth and Family Studies (2019) 10(2-3): 142-155

"dawned on me", at a somatic level, was an experience of "embodied knowledge" (Benner \& Wrubel, 1989, p. 42) in which I had grasped the meaning of the situation directly (not abstractly) as a result of being personally engaged.

In an interview the day before the dream, a relief staff member had described the hurt and anger of the residents, and I now realised that her comments had begun to work on me at a preconscious level. In our conversation, she had said:

It was a place for little kids to be. They came in with a lot of hurt and anger, and the teenagers do as well, and you are dealing with a lot of repercussions of their anger, so there's little opportunity to get into the head of the child and make a difference with their emotions. (...)

The staff was always there. But there was so much time taken up in behaviours, and dealing with behaviour, and trying to have the home run smoothly. In other words, "let's make our beds", "let's go to school", "let's get our homework done", "let's have our supper", "let's all clean up". There was so much time needing to be involved in having it all run smoothly, that even though staff were always there, for discussion, and "how are you feeling about this?", "what's happening?", "talk to me about it" - and a lot of that happened - it wasn't enough to make an impact on behaviour change. (Big House, Hillside and Parke Street relief staff member.)

Analysing the dream reminded me of a book of articles that I had read several years before entitled Rivers of Pain, Bridges of Hope (Davis, 1987). When I returned home from the week of site visits to the Valley Agency group homes, I pulled the book from my shelf and looked through it again. One of the first themes woven into Davis' discussion of residential group care was Victor Hugo's story of Les Misérables, and there were several references made to "darkness of the heart" (Davis, 1987, pp. 6-8). Davis says towards the end of his discussion, "At the micro-level, residential establishments often - rightly - go through their own revolutions when the 'darkness' becomes intolerable for both clients and staff" $(1987$, p. 8).

Apropos to the reference to "revolutions", I had heard from the same relief staff member quoted above that a "riot" had occurred at one of the group homes several weeks before my arrival. Residents locked staff in the office, broke windows, and "trashed" the kitchen and other parts of the house. The police had to be summoned to restore order.

The words and images shared by this worker along with my direct participation in the homes had made a deep impression on me, and awakened some insights that burst forth in the powerful dream experience. To this day, several years later, the dream images and the memories of the rapid process of interpretation that took place in the minutes after waking up early on that February 13th morning are readily accessible to me. Further, the phrase "heart of darkness" from Davis' writing echoed the title of Joseph Conrad's famous novel which I had not previously read. I did read it soon after this incident, and thus this haunting notion has since that time quite aptly 
International Journal of Child, Youth and Family Studies (2019) 10(2-3): 142-155

captured for me the deep and pervasive pain that I discovered, and after the dream further explored, lying at the heart of the residential care experience for both residents and staff members.

As the framework that emerged from this research study will make clear, responding to pain and pain-based behaviour is the major challenge for carework staff in group care settings. And as residential child and youth practitioners, we would do well not to allow ourselves to become distracted by "the mere incidents of the surface", to seek to discern the inner truth of the pain hidden within the daily reality of group home life and work, and to find ways to guide the young residents and ourselves out of the heart of darkness and into a collective sense of normality. To do so requires nothing less than a ceaseless striving for appropriate consistency, reciprocity, and coherence throughout our child and youth care practice. It is this struggle for congruence in service of the children's best interests that provides the unifying theme for the creation of a nurturing and healing extrafamilial environment - a true "home for the heart" (Bettelheim, 1974).

J.P.A., Victoria, Canada

\section{“We Don't Feel That Love”: Getting Research “On Track”}

Angela felt compelled to write a preface for her thesis that shared aspects of her own journey over the course, and as a result, of her research study. She did not intend this to be included in the Ministry report, but both her supervisor (Jim) and the Ministry Research Director urged her to keep it in the report, as it was a powerful statement and insight into the impact of this kind of research on the researcher, revealing often over-looked aspects of the research process itself. We include this preface here as the second example of the inner life and anxiety of the investigator in such pain-related studies. It illustrates the importance of recognizing and acknowledging, in an explicit and fulsome way, how the process of social science research often (if not always) is also a process of "re-searching the researcher."

My clients...continue to teach me what we all need to learn-that life can be brutally hard and simply beautiful, that we are stronger than we know (or might wish), and that the human heart shines most brilliantly when it is engaged and shared. (Mahoney, 2003, p. 11)

This study on the retrospective reflections of BC former youth in care on their experiences of removal, transitions and trauma has inspired a journey of my own self-discovery and introspective contemplation on the processes of doing research. As a Métis woman, novice social science researcher, child and youth care worker, mother, wife, friend, advocate, adversary, and carer, the dynamic and shifting elements of my social, professional, and personal roles often collide in spaces of tension. During this study what emerged was acceptance for my need to balance the tensions, acceptance that remaining in tension allows me to deeply and critically question my self, perspectives, privileges, values, beliefs, and biases in my research, writing, and practice. The purpose of this reflection is to explore the tensions that emerged during this study. This will be discussed in two integral ways: firstly, I will reflect on the process of interviewing, analyzing the 
voice data, and writing this research report; and secondly, I want to acknowledge how this research project personally inspired me to search out my own family roots.

The process of interviewing participants was challenging in many ways. As a child and youth care worker, graduate student, and clinical counselling intern, there were often times during the interviews when I had to hold back from reacting or responding to the participants. I have been educated and trained to be supportive of those with whom I work. Sitting and just listening, allowing them space to share their stories with me evoked so many tensions, feelings and thoughts. I am not suggesting that as researchers we do not respond or be transparent in how we interact with participants; rather, this is a reminder that sometimes we just need to listen, be quiet, and open to allow others the time, place and emotional space to share their stories, insights, and experiences. Sitting, listening, and taking in someone else's pain, was more difficult than I can articulate. This happened throughout the interviews, but during one in particular I had to step back and process how this young Indigenous woman's story affected me. What she told me was painful, for her and for me. Hearing someone else describe so many of my own deep, dark, painful, and lonely early life experiences made me feel like I was breathing in her pain, socked in my chest and straight to my heart. This is not because I have not heard life stories or experiences like my own before; particularly in my area of work, I have too often heard these stories and ones that I found much more painful than my own. What made this experience different was knowing that I had to sit in that tension and listen, knowing this was about her expressing her painful story to someone she does not know. I could not tell her that I had experienced so many of the same things, nor could I put on my counselling hat and ask reflective questions. I just needed to listen and absorb. Further, I felt an internal sense of dissonance between myself as a privileged Métis woman and graduate student, asking a First Nations woman about her life in care. After this interview, I felt overwhelmed-was I doing the right thing? Would I be able to express the meanings in my writing? What about my privilege as a researcher? What about my privilege as a Métis woman, who has light skin and lives in the tension of being of mixed ancestry? How can I approach this research in an ethical and socially just manner? I called my committee member on the phone, a woman whom I deeply admire and hoped would be able to understand what I was trying to process. In our conversation she reminded me that this research study was not a fixed end, that I could continue this work, and that I could continue to carry the tension of my identity and these stories into my future work. From that point on, I approached the interviews and this study in a different manner: it became not just about loss, grief, and pain, but also about love, hope, and future possibilities. It was not about taking apart or deconstructing the voices and stories of the participants; it was about presenting and amplifying them, coalescing their meanings.

Interviewing is a process, one that I found to be immensely engaging and problematic. As I was sitting and listening to the participants' stories, all of my senses were consciously heightened. I could smell the rain outside, the stale pizza boxes, and the coffee that had just been brewed. I could hear the sounds on the street, the pouring rain, people talking in the hallway, and the voice of the participant reverberating over all the sounds and reaching straight through to me. I could see 
the room, fluorescent lights, the shadows, and the furniture - and I could see them, and as we looked in each other's eyes it was in that moment I would know some of the pain, loss, love, and hope they were expressing to me. With all my senses engaged it was powerful, and their stories became embodied, they became tangible, and alive. But now came my worries: how could I ever express on paper the power of these moments? Without having been in this room, with all senses imminently engaged, how could someone else feel the meaning that was expressed? I believe we are feeling, sensing, relational, and holistic beings, our memories and experiences are so often enmeshed with our bodily senses. I worried (and still do) that in a textual document, the living, breathing, impact of their stories would be diluted in some way.

I made a mistake: I assumed that the interview process was going to be the most emotionally difficult part of this research study, and then came the analysis. I transcribed all the interviews, approximately two hundred pages of rich textual data on the life experiences, stories, narratives, perception, insights, and ideas of 20 young people who I had come to greatly respect and admire. Further, I felt protective of them and their life stories, and had great difficulty imagining how I could ever break down what they said into sections, parts or quotes. I started with a thematic analysis of the data, I developed global themes, organizing themes and basic themesthere were so many different themes. I met with my supervisor, and being the grounded theorist that he is, he asked a question that would change my entire perception of the data and the manner in which the report would be written. I had told him about all the themes, showed him the data maps I had created and the many quotes that I had sorted. He then asked if there was one central, overarching category or theme, something that connected all the data. I did not know how to answer that question, I left his office in some kind of existential haze. I spent three days re-reading all the transcripts and all I could see was a multitude of diverse experiences, though many were related. Then on that third day, I became frustrated, I could only see all the data at once, I was not able to break them down or centralize them, and I needed a break and decided it was time for a walk.

I live in a beautiful place, close to the lake and surrounded by the forest, and walking always clears my head, so I headed to the train tracks behind my house. I stepped onto the tracks and could hear and feel the crunch of the rocks and wood beneath my feet, I could hear the birds, and I could smell the crisp winter air. My thoughts were running through my head, so many themes, and so many experiences. I then realized maybe I was looking at the data the wrong way, maybe instead of seeing what was there, I need to look for what was not there. What was missing? Then, as the colloquial saying goes, a "light bulb went off" in my head, though maybe it was more like one thought shattering all the others, breaking through the darkness. There it was, what was missing-love. I stopped walking, and stood there silent. Is it love that is missing in their experiences of being in care? I turned around and headed home, back to the transcripts, and I spent the rest of the day re-reading their stories. There it was, or for that matter, was not, and in one participant's transcript he perfectly stated what youth in care are missing- "we don't feel that love." I had to go to my supervisor and explain what I was conceptualizing: I assumed he would 
think I was out of my mind. Our meeting went well; we poured through the data and the descriptions of love, and we both agreed this was a core category, but now this meant a shift in methodology, it was now a grounded theory approach. The next two months were also emotionally difficult, as comparative analysis is, at times, painstakingly slow and methodical.

It was time to write the final report; this process has taken many memos, drafts, and revisions. It has also been emotionally painful at times; I did not assume that editing would be this psychologically disruptive. I believe the most difficult thing, what has kept me awake at night and what is the crux of my worries, is my belief that there is no possibility that I could ever be able to convey the meanings that were shared by the participants; that I could ever write in a textual document the embodied meaning of some of their life stories and experiences that were conveyed to me in the interviews. I did not want to leave any of their stories behind, I did not want to lose the power of their words, and I did not want to dishonour their life experiences in any way. I have done my best, with the help and support of my supervisor and committee members, to convey exactly what was voiced by the youth in this study. I know that I will carry the tension, weight, and power of these young people's stories with me in all my future work.

I have been critically engaged throughout this study, while interviewing, writing, and thinking about how to present the insights and perspectives of those who so generously shared some of their life experiences with me. During the past year of working on this research project I have also gone through my own process of self-discovery. In particular, the participants inspired me to seek out my family history that has been missing. I do not know my biological father, and I know very little about my Métis family history in Fort Qu'Appelle, Saskatchewan. Now, this may not be the place or space to divulge my own painful story, but sharing how the participants' stories impacted me is fundamentally important if I am to be as transparent as possible in the research process. Further, I want to express that doing research affects us, it can be painful and inspiring, and it can push us to deeply reflect on who we are and to do better work. I searched for my family history, and I found my lineage, those family names that bring together my genealogy and our historical imprint on our homeland of Saskatchewan. Sadly, I also found out that my biological father passed away last summer. The situational irony is certainly not lost on me, nor is the impending flow of guilt that I had waited too long to find him. But I was not ready, for the past 30 years I have wondered what happened to him, and I was not ready to know until after I had experienced this process over the past year. My biological father and I will never have the chance to meet again, to find closure, or possibly to have developed a new relationship. And I am reminded of one of my favourite quotes: "it's being ripped from love that causes the wound in the first place and its only love in the end that heals it" (Wagamese, 2009, p. 13). Losing a loved one or a loving connection is never easy; it can be brutally painful, yet in all those dark moments there may be some light. Maybe we have the love of our friends, extended family, children, community, or our pets-love can be found again, it can be re-established, it can grow out of dark places, and it can offer us a chance to heal. My hope for those who so generously agreed to participate in this research study is that they know they inspired at least one person to re-establish a loving connection that 
International Journal of Child, Youth and Family Studies (2019) 10(2-3): 142-155

was once lost, I may not have found it in the way I imagined or dreamed it could be, but I am eternally grateful for the journey and the chance to utilize the love that I have in my life to heal the wounds of my past.

In deep gratitude, Angela Scott

\section{Discussion and Implications}

For each of us, as the authors of these Prefaces, reading over these excerpts years later (in Jim's case, after almost 20 years), we vividly remember the experiences described. This intensity of emotion seems important to examine and understand, both in relation to its implications for undertaking rigorous social science research as well as for equipping researchers to be prepared for the challenges and opportunities they will likely encounter. The growing literature on Indigenous research methodologies (e.g., Absolon \& Willett, 2005; Carrière \& Richardson, 2017; Kovach, 2009; Smith, 2002) does consistently address the issue of the intersection of researcher and research subject experiences. On researcher preparation, Kovach (2009) stated, "The term researcher preparation describes the experiential aspect of the research. It is about process. There are aspects of this research approach that required preparation and choices grounded in inward knowing that arises from personal experience" (p. 49). While it will not always be possible to predict specific impacts, asking researchers (especially students and novice researchers) to explore their personal histories relevant to the research topic may make the process of inquiry more reflexive and transparent. For example, Carrière begins her article reporting on her research into the adoption of Métis children with a section on personal location in which she discloses her own Métis roots and adoptee status (Carrière, 2017, p. 77).

While Jim's preface offers an account of how a nighttime dream (a nightmare, actually) led to key research findings, Angela's explores how a flash of insight while walking on railway tracks led to not only her core findings but also deep personal insight and change; both involve the researcher's deep emotional engagement in the research process and with the study participants. For Angela, her engagement with the pain of the young interviewees, and her willingness to explore her resulting personal tension and pain, led to both more understanding of their lives (being removed from family and living in care) and some profound psychoemotional resolutions in her own personal and family life. Kovach (2009) weaves her own journey of personal, communal, and spiritual re-discovery throughout her account of exploring research epistemologies and methodologies in search on Indigenous ways of knowing and inquiry. Interestingly, paralleling Jim's experience, she recounted "paying attention to my dream life" (2009, p. 180) and journaling during her data gathering and analysis.

We realize that both of our stories (in concert with much Indigenous writing) are raising some very fundamental issues and challenge some longstanding tenets of social science research. What about the pursuit of objectivity and dispassionate scientific research? Does allowing the feelings and emotions of the researcher to enter the research process bias the research process and 
even risk invalidating the findings? Our position parallels that of Devereux, namely that "the behavioral scientist cannot ignore the interaction between the subject and observer in the hope that, if he [sic] but pretends long enough that it does not exist, it will just quietly go away" (Devereux, 1967 , p. xviii), and that ignoring this dimension leads to significant "defects of behavioral science" (p. xvii). We would maintain that following a clear and rigorous research method and process provides the context for considering the researcher's own responses both as data, in their own right, and as pathways to deeper insight into the lived experiences of research subjects. In the grounded theory literature, such insight is encompassed in the notion of "theoretical sensitivity" (Glaser, 1978).

At the same time, Angela felt wary (and to a degree still does) about sharing her personal reflections even though they are now published and available to anyone who accesses her thesis on the internet. Why? Because it was so raw and vulnerable for her, and because this research study had affected her deeply as some of the young people's stories were also hers. Their experiences were parallel to her own: she too had experienced many similar losses. Angela has spent many years in her practice and in her learning being taught that it is not acceptable to be a "wounded healer", or to be familiar or too close with our "clients"; instead, we are to be objective in our views, research, and practices. If she were to be transparent and open about her experiences, what would others think of her? Would they believe she was not a good practitioner? Could this affect her career and livelihood? Would people question her ethics, her ability, and her capacity in child and youth work? It is likely that some people do, but she knows why she is committed to this work, and what it means to her and - more importantly - to those with whom she works. By becoming more aware of her own background and the significance of the experiences she has carried with her, Angela knows she is better able to empathize and respond effectively to children, youth, and families struggling and in pain. In keeping with this commitment, she needed to critically reflect on how her research study affected her, just as she needs to reflect (critically and deeply) daily on how her practice affects her and those with whom she works.

In addition to the Indigenous writing previously cited, there is a stream of European and North American social science literature on these issues that can be traced back to Dilthey's explorations of "human studies" (Rickman, 1976). In more recent times, his explorations are reflected in discussions of "human inquiry" (Reason \& Rowan, 1981), "naturalistic inquiry" (Lincoln \& Guba, 1985) and "researching lived experience" (van Manen, 1990).

The purpose of this article is not to resolve these very large issues, but rather to raise them and underline their significance for research on, and researchers engaged in, the lived experiences of human beings. This seems to us to be especially important for research in child welfare and child and youth care work that will almost always involve psychoemotional pain.

On the basis of our research experiences in the two studies presented here, we believe that students and beginning researchers in the social sciences need to be introduced to the psychoemotional dimensions of the researcher's own experiences in the research process in order to both 
International Journal of Child, Youth and Family Studies (2019) 10(2-3): 142-155

sensitize them to potential research findings (often hidden), and prepare them for the possible (even likely) impacts on themselves as researchers, professionals, and human beings. 
International Journal of Child, Youth and Family Studies (2019) 10(2-3): 142-155

\section{References}

Absolon, K., \& Willett, C. (2005). Putting ourselves forward: Location in Aboriginal research. In L. Brown \& S. Strega (Eds.), Research as resistance: Critical, Indigenous and antioppressive approaches (pp. 97-126). Toronto, ON: Canadian Scholars' Press.

Anglin, J. P. (2002). Pain, normality and the struggle for congruence: Reinterpreting residential care for children and youth. New York, NY: Routledge.

Anglin, J. P., \& Scott, A. (2016). "We don't feel that love”: Retrospective reflections on the experiences of removal, transitions and trauma from former youth in care (Report). Victoria, BC: Ministry of Children and Family Development.

Berridge, D. (1986). Children's homes. Oxford, UK: Blackwell.

Carrière, J., \& Richardson, C. (2017). Calling our families home: Métis people's experiences with child welfare. Vernon, BC: JCharlton.

Devereux, G. (1967). From anxiety to method in the behavioral sciences. Paris, France: Mouton $\&$ Co.

Glaser, B. G. (1978). Theoretical sensitivity. Mill Valley, CA: Sociology Press.

Glaser, B. G., \& Strauss, A. L. (1967). The discovery of grounded theory : Strategies for qualitative research. Chicago, IL: Aldine.

Heshusius, L., \& Ballard, K. (Eds.). (1996). From positivism to interpretivism and beyond: Tales of transformation in educational and social research (the mind-body connection). New York, NY: Teachers College Press.

Kovach, M. (2009). Indigenous methodologies: Characteristics, conversations, and contexts. Toronto, ON: University of Toronto Press.

Lincoln, Y. S., \& Guba, E. G. (1985). Naturalistic inquiry. Beverly Hills, CA: Sage.

Polanyi, M. (2009). The tacit dimension. London, UK: Routledge. (Original work published 1966).

Reason, P., \& Rowan, J. (Eds.). (1981). Human inquiry: A sourcebook of new paradigm research. New York, NY: John Wiley and Sons.

Rickman, H. P. (Ed.). (1976). Dilthey: Selected writings. Cambridge, UK: Cambridge University Press. 
International Journal of Child, Youth and Family Studies (2019) 10(2-3): 142-155

Scott, A. (2016). "We don't feel that love": Retrospective reflections on the experiences of removal, transitions and trauma from former youth in care (Master's thesis). University of Victoria, Victoria, BC.

Smith, L. T. (2002). Decolonizing methodologies: Research and Indigenous peoples. London, UK: Zed Books.

van Manen, M. (1990). Researching lived experience: Human science for an action sensitive pedagogy. London, ON: Althouse Press (University of Western Ontario). 